\title{
Water Environmental Management in Industrial Park - A Case Study of Xinjin in Chengdu City
}

\author{
Xintuo Chen ${ }^{1}$, Yao Ding ${ }^{1,2}$, Chengyue Lai ${ }^{1}$, Ke Zhong ${ }^{1}$, Yiyao Wang ${ }^{1}$, Zhaoli Wang ${ }^{1,}$ * \\ ${ }^{1}$ Chengdu Research Institute of Environmental Protection Science, Chengdu, China \\ ${ }^{2}$ College of Architecture \& Environment, Sichuan University, Chengdu, China
}

Email address:

9755014@qq.com (Xintuo Chen), 532286821@qq.com (Zhaoli Wang)

${ }^{*}$ Corresponding author

\section{To cite this article:}

Xintuo Chen, Yao Ding, Chengyue Lai, Ke Zhong, Yiyao Wang, Zhaoli Wang. Water Environmental Management in Industrial Park - A Case Study of Xinjin in Chengdu City. International Journal of Environmental Monitoring and Analysis. Vol. 6, No. 5, 2018, pp. 125-130. doi: $10.11648 /$ j.ijema.20180605.11

Received: October 22, 2018; Accepted: November 5, 2018; Published: November 30, 2018

\begin{abstract}
The mode of industrial park is becoming a vital national strategy of circular economy in China and a means to enhance energy efficiency, environmental performance, and economic competitiveness. It is becoming increasingly important to control the discharge of industrial wastewater from industrial parks in order to reduce water pollution. In this paper, as taking Chengdu Xinjin chemical cluster area for example, industrial layout of the park, environmental pollution treatment measures and management situation was analyzed surrounding with water environmental issues, factors of industrial park, like layout planning, industrial structure, management mode etc. were considered as significant influence on water environment. Enterprises in the park have different discharge standards and without any supervision. The influent of the wastewater treatment plant in the park is unstable, and the total phosphorus discharge exceeds the standard for a long time, and there is no large emergency pool in the park to prepare for sudden pollution incidents. In order to solve these problems, this paper puts forward some measures, such as setting up on-line monitoring, improving the standard of enterprise water discharge, and establishing emergency command system etc. In addition, some suggestions were put forward on how to improve the industrial park water environment status and management level, to provide references for the development of industrial park. The results could have supports for the design and optimization of wastewater treatment processes, as well as for evaluation of how centralized wastewater treatment plants can help to control water pollution.
\end{abstract}

Keywords: Water Environmental Protection, Industrial Parks, Environmental Management

\section{Introduction}

Since the implementation of China's reform and opening-up policy, industrial parks of different levels and types have sprung up all over the country and played an outstanding role in promoting economic development $[1,2]$. However, with the growth of economic aggregate and the increase of resources and energy consumption, industrial parks have also become one of the important pollution sources for the atmosphere, water, soil and ecology etc., brought a series of pollution, and seriously affecting people's health and living environment [3].

How to control the impact of industrial park on the surrounding environment is the focus of current attention, and the park sewage treatment and water environment management is an important component [4]. Therefore, scientific development planning of industrial parks, rational formulation of sewage treatment model and efficient management are of great significance for the development of green economy and environmental improvement [5-7]. Based on the investigation and analysis of the existing problems [8-16], sewage treatment and management methods in the industrial park, in this work, Xinjin Chemical Industry Cluster Zone has been taken as an example to study the sewage treatment mode, so as to provide reference for the environmental management of the industrial park. 


\section{General Situation of Sewage Treatment}

\subsection{Sewage Treatment Mode}

The study object of this work is Chengdu Xinjin Chemical Industrial Cluster Area (CCICA), which was established in accordance with "Chengdu Industrial Development Layout Plan" in 2007, as a professional industrial cluster and provincial-level industrial park in Sichuan Province. Infrastructure facilities of the park are self-contained, including water, electricity, gas, roads, communications, optical fiber, sewage pipe networks, etc. Drainage in the park adopted rain and sewage diversion system. The drainage pipes built by each enterprise unit were connected to the main sewage pipes in the park. Some key sewage discharge enterprises set up their own industrial wastewater treatment facilities and the sewage was discharged into the main sewage pipes after being treated, finally, the wastewater flows into the Minjiang River after being disposed centrally by sewage treatment plant in this park, as shown in figure 1 .

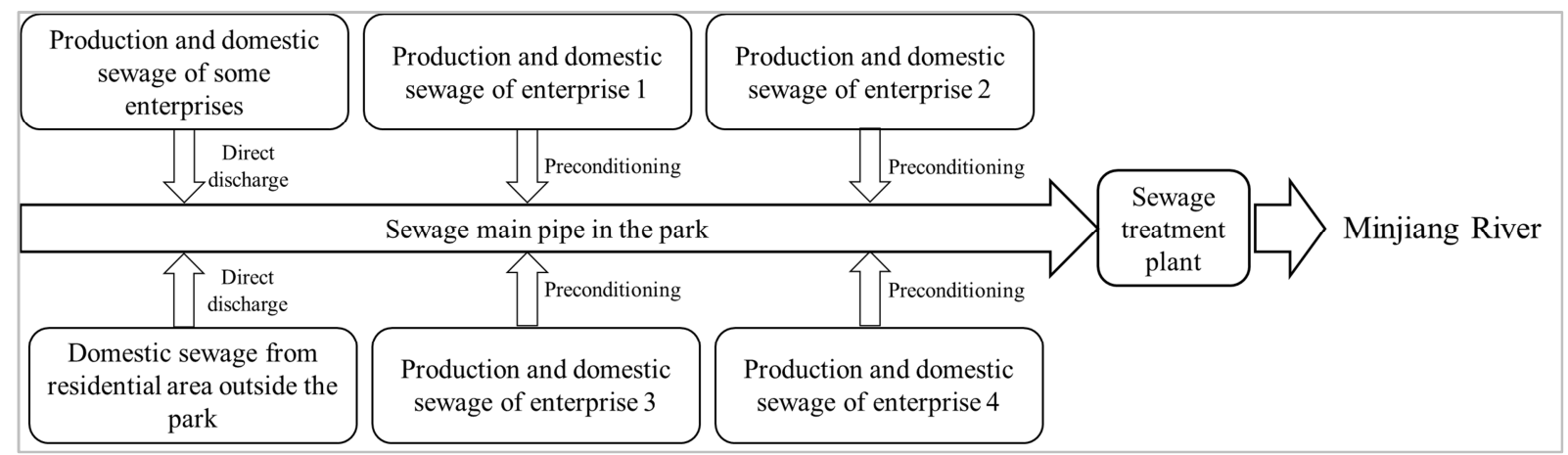

Figure 1. Sewage treatment diagrammatic sketch of CCICA.

At present, there are more than 40 enterprises in this park. The sewage treatment plant in park, with the designed daily sewage treating capacity of 10,000 tons, is responsible for the treatment of industrial production and domestic wastewater from enterprises in the park and domestic wastewater from some residents outside the park. The daily wastewater from the enterprises in park is about 7,000 tons, and an additional 1,000 tons of domestic sewage from some residential area outside of the park goes into the sewage plant, serving about 10,000 people. Anoxic/aerobic activated sludge process (A/O process) was used as the technology route in this plant, and the effluent is discharged according to the First Level A of "Discharge Standard of Pollutants for Municipal Wastewater Treatment Plant (GB18918-2002)", which is $0.5 \mathrm{mg} / \mathrm{L}$.

\subsection{Investigation of Sewage Treatment}

By investigating some sewage treatment plants of enterprises in the park, combining with the technical data of water quality monitoring report and environmental impact assessment report, the main problems are found as follows.

(1) Sewage treatment plants can not meet the requirements of total phosphorus (TP) discharge

Figure 2 is the average water quality data of the park sewage treatment plant for each quarter in 2014 2016. The average TP concentration of each quarter in three years was calculated. The results showed that the influent concentration of TP in the first quarter was $12.9 \mathrm{mg} / \mathrm{L}$, and the effluent concentration was $3.6 \mathrm{mg} / \mathrm{L}$ (removal rate $72 \%$ ). The treatment effect was obvious, but it still did not match the First Level A of Standard GB18918-2002 (0.5mg/L); the influent and effluent concentration of TP in the second quarter were $28.2 \mathrm{mg} / \mathrm{L}$ and $28.1 \mathrm{mg} / \mathrm{L}$ respectively, with no reduction and tail water discharged directly; the influent and effluent concentration of TP in third quarter were $26.5 \mathrm{mg} / \mathrm{L}$ and $16.5 \mathrm{mg} / \mathrm{L}$ respectively (with removal rate $38 \%$ ), but the TP value of effluent after treatment has not yet reached the First Level A standard; the TP concentration of influent and effluent in the fourth quarter were $4.35 \mathrm{mg} / \mathrm{L}$ and $4.34 \mathrm{mg} / \mathrm{L}$ respectively, which was not cut down and the tail water still discharged directly. The highest concentration of TP in the second and third quarter of these years is due to the peak production of phosphorus-related producing enterprises in the park and this phenomenon has existed for a long time.

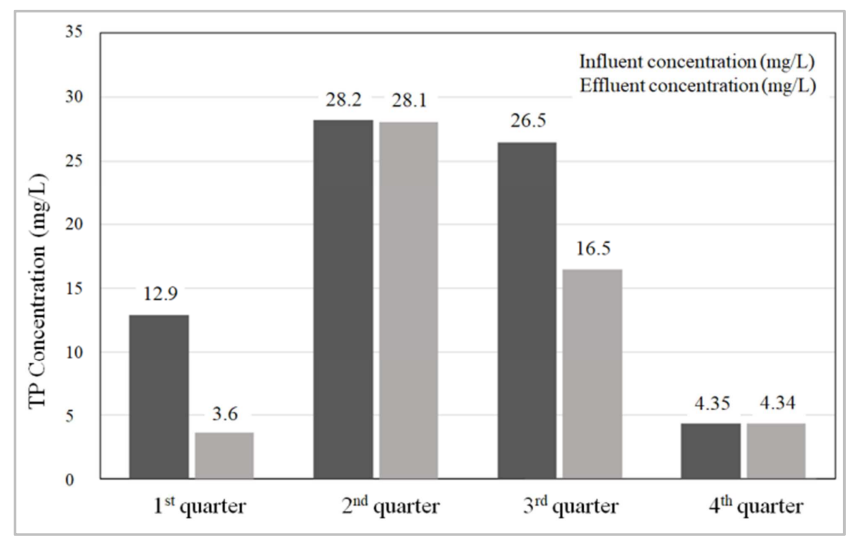

Figure 2. Average TP concentration of influent and effluent from the park sewage treatment plant for each quarter in 2014 2016.

The plant is designed according to TP in the water below $5 \mathrm{mg} / \mathrm{L}$. All effluent indexes except TP meet the prescribed discharge standard. Since TP concentration of influent is much too higher than the design value, and the biological denitrification effect of the existing treatment process is still available but the phosphorus removal effect is weak, which can not meet the requirement of reducing TP to blow $0.5 \mathrm{mg} / \mathrm{L}$. 
(2) Quality of production wastewater from enterprises is unstable and varies greatly

Through on-site investigation, refer to the water quality monitoring report of enterprises. Preliminary understanding of the production wastewater in phosphorus discharging related enterprises was made.

Enterprise A is a factory mainly based on production of glyphosate and other pesticide products, with two production area, and wastewater is combined into a drainage outlet after pretreatment by biochemical treatment process, finally flows into the sewage treatment plant. Under normal production conditions, the daily drainage capacity is about 240 tons in accordance with the first-level of Integrated Wastewater Discharge Standard (GB8978-1996), TP concentration requirement is lower than $0.5 \mathrm{mg} / \mathrm{L}$. According to the monitoring results, the TP concentration before and after treatment was $6.89 \mathrm{mg} / \mathrm{L}$ and $5.26 \mathrm{mg} / \mathrm{L}$ on January 7,2016 . The effluent's TP exceeded the discharge requirements implemented by this factory, but was still far lower than that of effluent in the sewage treatment plants in the same period. On April 2, 2016, TP of the outfall in old factory before and after treatment was $11.3 \mathrm{mg} / \mathrm{L}$ and $1.81 \mathrm{mg} / \mathrm{L}$ respectively, the TP value of outfall in new factory before and after treatment was $12.4 \mathrm{mg} / \mathrm{L}$ and $3.82 \mathrm{mg} / \mathrm{L}$. TP concentration of the both outfalls exceeded the enterprise's operative standard, but was still far lower than average $\mathrm{TP}$ value in the effluent of wastewater treatment plant in the park on that day. The monitoring results on May 18, 2016 showed that the TP concentration at the $1 \#$ rainwater outlet was $1.58 \mathrm{mg} / \mathrm{L}$ and that at the $2 \#$ sewage outlet was $0.86 \mathrm{mg} / \mathrm{L}$, which also exceeded the implementation standards. By July 8, 2016, TP concentration was $23.8 \mathrm{mg} / \mathrm{L}$ before treatment and $0.62 \mathrm{mg} / \mathrm{L}$ after treatment. TP reduction effect was very good, but still failed to meet the requirement. According to the information obtained from the person in charge of the factory, it is in a state of shutdown, the new wastewater treatment plant is in the stage of acclimatization of activated sludge and commissioning of the whole plant, no industrial wastewater is discharged into the wastewater treatment plant of the park for the time being. However, historical data show that the high phosphorus wastewater treatment capacity of the plant is limited and it is one of the important point sources of pollution emissions.

Enterprise B is a manufacturer engaged in the production of potassium hydroxide, potassium dihydrogen phosphate and other chemicals. It uses a neutralization sedimentation tank to pretreat the production wastewater with a daily discharge of 200 tons according to the third-level of Integrated Wastewater Discharge Standard (GB8978-1996) with no limit to the phosphorus. The sampling monitoring report on May 2, 2016 showed that the total phosphorus concentration before treatment was $4.84 \mathrm{mg} / \mathrm{L}$, and $1.38 \mathrm{mg} / \mathrm{L}$ after treatment, which was far lower than the average concentration of TP in the influent of the wastewater treatment plant in the park on that day. According to on-site investigation, the neutral sedimentation tank in the factory mainly contains the waste water generated in the production process, the cleaning waste water and the cooling water of the equipment. The design capacity of the neutral sedimentation tank is large, and it also plays an emergency regulation role. With a $\mathrm{PH}$ on-line monitor in the pool, effluent is finally adjusted to neutral and discharged into the pipe network. It is preliminarily deduced that inorganic phosphorus is the main component of total phosphorus in wastewater, and the effect of reducing total phosphorus by neutralization process is limited.

In addition, there are four small and medium-sized enterprises involved in the production of sodium hexametaphosphate, lubricating oil, phosphating coatings and phosphorus-containing pesticides, all of which have a certain amount of phosphorus-containing wastewater discharged into the main pipe, but there is no corresponding record and test report, and nor is there any pre-processing facilities inside the enterprises.

Through investigation, it is found that the quality and quantity of wastewater produced by various enterprises are very different, and there is no uniform discharge standard, which will inevitably cause difficulties to control the quality of the influent water of the wastewater treatment plant in the park and affect the final treatment effect. Other enterprises in the park still need thorough and comprehensive investigation to find out the emission of pollution sources.

(3) Daily supervision is not enough and emergency response is lagging behind

The management of the park is still inadequate: the frequency of environmental monitoring is not enough, some monitoring reports involved in the detection indicators are not comprehensive, not conducive to the next in-depth analysis of the water quality of sewage treatment plants and the formulation of the corresponding dephosphorization process. Emergency response and disposal among discharge enterprises, sewage treatment plants, monitoring units and competent departments are relatively lagging behind after emergencies such as excessive discharge in the park, which can not be properly solved.

\section{Analysis and Discussion}

In view of the above found problems, the main reasons are:

(1) The daily investigation and supervision work is not enough and comprehensive

The monitoring frequency of water quality in key enterprises is relatively low, and there is no complete information about the wastewater discharged by all enterprises in the park, and the operation status of all enterprises discharging phosphorus-related pollutants has not been found out. Some enterprises do not have relevant monitoring records, there is a phenomenon of missing detection, from the current grasp of information can not fully determine the specific point source location and quantity.

(2) The pretreatment of wastewater is not in place

Enterprises in the park have no unified standards for wastewater treatment and discharge, not only resulting in complex and difficult to accurately identify the composition of the sewage, but also caused difficulties in management, for 
example, pollution sources and accountability can not be clearly defined. Some enterprises require more stringent, but their own wastewater treatment process is relatively backward, can not fully meet the requirements of stable discharge standards; some enterprises have low implementation standards, such as the third-level of Integrated Wastewater Discharge Standard (GB8978-1996), which does not restrict the total phosphorus, resulting in the neglect and omission of TP in the operation and monitoring departments of enterprises, and ultimately lead to the failure to accurately find the pollution sources and discharge conditions; some enterprises even do not have pretreatment facilities, directly discharged the wastewater to sewage pipe network, thereby increasing the operational burden of sewage treatment plants in the park.

(3) Enterprises lack emergency equipment and management mechanism

Some enterprises do not have their own emergency pools or regulating pools to temporarily store the excessive discharge wastewater caused by emergencies. Once similar incidents occur, the wastewater will directly enter the sewage treatment plant without effective treatment, which will inevitably affect the final effluent quality, and even cause destructive pollution accidents. There are still no effective measures to ensure response as soon as possible.

(4) Sewage treatment plant lacks emergency regulating pool and dephosphorization process.

At present, the technology adopted is no longer suitable for the treatment of high phosphorus wastewater, and the capacity to reduce TP is limited. There is no large-scale emergency pool for the temporary storage of sudden high phosphorus wastewater in the plant park area, and there is no buffer room. Additional dephosphorization links, such as adding agent flocculation and dredging, are also absent in the process. The lack of facilities and technology resulted in TP reduction unable to meet the standard requirements.

(5) Low efficiency of information communication and feedback

The information communication among enterprises, sewage treatment plants and management departments is not smooth enough. When problems occur, it is difficult to establish contact immediately and conduct accident investigation. With the gradual elimination of accident traces over time, it is difficult to accurately analyze the causes of the accident and formulate the next step of countermeasures.

\section{Conclusion}

The key to manage the water environment of industrial parks is to ensure the strict implementation of sewage treatment according to certain standards, timely identify unexpected situations and make emergency measures quickly. Through visiting investigation, cause analysis and expert consultation, based on the above problems mentioned, the work suggestions are as follows:

(1) Thoroughly investigate park enterprises involved in phosphorus wastewater discharge and analyze water quality
Only a few enterprises' water quality monitoring reports show that the wastewater produced by the enterprises has been pretreated by themselves and entered the wastewater treatment plant in the park. Except for one of the monitoring reports which does not contain the TP concentration, the other total phosphorus effluent concentrations exceed the First Level A of GB18918-2002 Standard, but are also far below the influent concentration of the wastewater treatment plant in the park. It is necessary to investigate other enterprises, not excluding the situation of stolen discharge, improper operation and production accidents. Find out the distribution of point source and the total amount of discharge, further analyze the water quality, provide the basis for phosphorus removal transformation of the treatment plant.

(2) Conduct a comprehensive inspection of the operation and maintenance of the sewage treatment plant in the park.

According to the follow-up investigation, the effluent quality from first quarter to fourth quarter of 2017 is in good condition, only TP is unstable. The total phosphorus removal rate was $72 \%$ on Feb. 17, but it still did not reach the First Level A; On April 21, total phosphorus was not reduced, and tail water was discharged directly; On August 16, total phosphorus removal rate was $38 \%$, the treatment effect was not obvious and did not reach standard; On November 15, total phosphorus was not reduced and tail water was discharged directly.

It is suggested that the engineering process should be checked and analyzed, and the inhibition of influent water quality on the biochemical treatment of wastewater, such as acidity, salinity, heavy metals and toxic pollutants, should not be excluded. In the transitional stage before the sewage treatment plant is reformed, necessary measures should be taken to control the total phosphorus discharge, such as artificial chemical precipitation phosphorus removal, sediment dredging etc.

(3) Establish a clear and unified standard for the treatment and discharge of industrial waste water

According to the industrial structure of industrial park and the process of wastewater treatment plants in park, a reasonable, clear and unified standard for the treatment and discharge of industrial wastewater should be established. It is not only convenient for enterprise management in the park, but also can quickly trace back to unexpected events. Moreover, the quality and quantity of wastewater can be strictly controlled. Finally, ensure the stable operation of the sewage treatment plant and continuously improve the overall water environment.

At present, the total phosphorus treatment capacity of the wastewater treatment plant in the park is weak, so the concentration of TP in the influent should be limited; besides $\mathrm{TP}$, all water quality indexes of the influent are equal to those of domestic sewage. The TP concentration of urban sewage in Chengdu is $3 \sim 4 \mathrm{mg} / \mathrm{L}$. All kinds of mature processes can achieve the effluent quality of First Level A, whose total phosphorus is lower than $0.5 \mathrm{mg} / \mathrm{L}$.

In view of above two points, combined with current 
situation of water environment, water quality characteristics and future development needs of Chengdu, referring to the operation and maintenance methods of sewage treatment plants at home and abroad, and taking into account the normal operation and maintenance of enterprises in the park and abnormal working conditions, as well as the treatment of wastewater treatment plants in the park, in order to ensure the stability of effluent quality, the TP concentration in effluent should be basically consistent with that in domestic sewage after self-treatment by enterprises in the park. It is suggested that the discharge standard should be carried out according to the Third Level of "Discharge Standard of Pollutants for Municipal Wastewater Treatment Plant (GB18918-2002). The total phosphorus of effluent should be strictly controlled, that is, the concentration is less than $5 \mathrm{mg} / \mathrm{L}$.

For enterprises with large phosphorus emissions, they should also be forced to establish emergency facilities, such as adjusting pools or emergency pools which can withstand shock loads and risk emissions, to deal with emergencies for at least 24 hours and to minimize the risk of pollution.

(4) Technical transformation of sewage treatment plant in the park

The technical transformation of the sewage treatment plant should be completed within the shortest time to ensure long-term stable operation. In view of the influent with high TP concentration, increase dephosphorization process links, and the phosphorus constituent (soluble organic phosphorus, insoluble organic phosphorus and phosphate) with the content in the influent also should be analyzed to determine the dosage of chemically assisted phosphorus removal agent. The technical scheme provided by bidding unit should be fully demonstrated and analyzed, and an economical and applicable project implementation scheme should be worked out.

Ensure that under normal operating conditions for sewage treatment plant in park, that is, when TP concentration of influent is less than or equal to $5 \mathrm{mg} / \mathrm{L}$, it can reach the discharge standard $(0.5 \mathrm{mg} / \mathrm{L})$, and meet the requirements of the plant under abnormal operating conditions. At the same time, on-line monitoring facilities for total phosphorus can be added to monitor the dynamic condition of the effluent, large emergency reservoirs should be built to cope with emergencies and avoid serious pollution incidents.

(5) Further improve the management of the park operation

On the basis of current operation and management, the supervision and guarantee of the park should be further strengthened. Enterprises and Park sewage treatment plants themselves should establish and improve sewage discharge management system, add TP on-line monitoring facilities, strictly control effluent concentration according to new standards and do well in monitoring, operation and maintenance. Report problems promptly and take effective measures to implement specific departments and personnel. The competent authorities and supervisory departments concerned shall strengthen supervision and take measures such as intensive monitoring and on-site inspection to ensure the sustainable development of the park. An emergency response mechanism should be established to ensure the smooth flow of information at an important moment, and measures should be taken in the shortest possible time to maintain good water environment.

\section{References}

[1] Feng Wu-jun, Mao Yu-ru, Chen Hong, etc. Study on Development Pattern of Circular Economy in Chemical Industry Parks in China [J]. Modern Chemical Industry, 2007, 27(3): 7-10.

[2] Xie Zhi-cheng, Zhao Wen-xi, Xu Ya-peng, etc. Discussions on Sewage Treatment Mode of Chemical Industry Zone [J], Environmental Science and Technology, 2012, 35(12): 278-281.

[3] Xu Zu-xin, Qu Ji-ning, Fu Wei. Control Route and Policy Approach of Waste Water in Industrial Area [J], Environmental Protection, 2005, 32(1): 30-32.

[4] Yu Guang-xian, Sun Yan. Emerging Economies Loop in Hangzhou Bay: Visit Shanghai Chemical Industry Park [J], China Petrochemical, 2005, 27(8): 28-30.

[5] Chen Jia-xiang. Study on The Development of modern Industrial Chemical Zone with Cyclic Economy-A Case Study of Nanjing Chemical Industrial Zone [J], Economic Geography, 2006, 26(3): 438-442.

[6] Xie Jia-ping, Kong Ling-cheng, Ji Wei. The Industrial Development Mode of Chemical Industry Parks-Take the Industry Parks in Yangtze River Delta as An Example [J], Journal of Shijiangzhuang University of Economics, 2009, 32(1): 8-13.

[7] Zhang Li-na, Chen Yu, Zhang Shu-shen. Discussion on Eco-Industrial Park Water Management Model [J], Environmental Science and Technology, 2006, 29(8): 75-76, 81 .

[8] Linlin Liu, Jian Wang, Haodong Song, Jian Du, Fenglin Yang. Multi-period water network management for industrial parks considering predictable variations [J], Computers \& Chemical Engineering, 2017, 104(9): 172-184.

[9] Guizhen He, Ingrid J. C. Boas, Arthur P. J. Mol, Yonglong Lu. What drives public acceptance of chemical industrial park policy and project in China? [J], Resources, Conservation and Recycling, 2018, 138(11): 1-12.

[10] Yupeng Fan, Qi Qiao, Chaofan Xian, Yang Xiao, Lin Fang. A modified ecological footprint method to evaluate environmental impacts of industrial parks [J], Resources, Conservation and Recycling, 2017, 125(10): 293-299.

[11] Guoxuan He, Jin Yang, Yi Lu, Saige Wang, Bin Chen, Tasawar Hayat, Ahmed Alsaedi, Bashir Ahmad. Ternary emergetic environmental performance auditing of a typical industrial park in Beijing [J], Journal of Cleaner Production, 2017, 163(10): 128-135.

[12] Sha Long, Lin Zhao, Tongtong Shi, Jingchen Li, Jiangye Yang, Hongbo Liu, Guozhu Mao, ZhiQiao, Yongkui Yang. Pollution control and cost analysis of wastewater treatment at industrial parks in Taihu and Haihe water basins, China [J], Journal of Cleaner Production, 2018, 172(20): 2435-2442. 
[13] Peng Kang, Linyu Xu. Water Environmental Carrying Capacity Assessment of an Industrial Park[J], Procedia Environmental Sciences, 2012, 13: 879-890.

[14] Xiaoqian Song, Yong Geng, Huijuan Dong, Wei Chen. Social network analysis on industrial symbiosis: A case of Gujiao eco-industrial park [J], Journal of Cleaner Production, 2018, 193(20): 414-423.

[15] Linlin Liu, Jian Wang, Haodong Song, Jian Du, Fenglin Yang.
Multi-period water network management for industrial parks considering predictable variations [J], Computers \& Chemical Engineering, 2017, 104(2): 172-184.

[16] Zhe Liu, Michelle Adams, Raymond P. Cote, Yong Geng, Yongzhi Li. Comparative study on the pathways of industrial parks towards sustainable development between China and Canada [J], Resources, Conservation and Recycling, 2018, 128 : 417-425. 